\title{
Sacando a los caciques de la oscuridad del olvido. Etnias chachapoya y chilcho
}

Les caciques tirés de l'oubli. Ethnies Chachapoya et Chilcho

Rescuing caciques from oblivion: the Chachapoyas and Chilcho ethnic groups

Inge Schjellerup

\section{(2penEdition}

Journals

Edición electrónica

URL: http://journals.openedition.org/bifea/3342

DOI: 10.4000/bifea.3342

ISSN: 2076-5827

Editor

Institut Français d'Études Andines

Edición impresa

Fecha de publicación: 1 abril 2008

Paginación: 111-122

ISSN: 0303-7495

Referencia electrónica

Inge Schjellerup, «Sacando a los caciques de la oscuridad del olvido. Etnias chachapoya y chilcho », Bulletin de I'Institut français d'études andines [En línea], 37 (1) | 2008, Publicado el 01 octubre 2008, consultado el 27 noviembre 2020. URL : http://journals.openedition.org/bifea/3342 ; DOI : https:// doi.org/10.4000/bifea.3342

\section{c) $(1) \odot$}

Les contenus du Bulletin de l'Institut français d'études andines sont mis à disposition selon les termes de la licence Creative Commons Attribution - Pas d'Utilisation Commerciale - Pas de Modification 4.0 International. 


\title{
Sacando a los caciques de la oscuridad del olvido. Etnias chachapoya y chilcho
}

\author{
Inge Schjellerup*
}

\begin{abstract}
Resumen
Las investigaciones de los últimos años permiten identificar a unos caciques como unos importantes actores en el escenario colonial y sacan a la luz a unas etnias desconocidas. Revelan también los fuertes agravios que sufrieron. El artículo trata de iluminar sucesos y casos en el siglo XVI en los departamentos de Chachapoyas y de Huallaga basados en trabajos de campo en arqueología y antropología y en investigaciones en los archivos de la historia peruana.
\end{abstract}

Palabras clave: nordeste del Perú, etnohistoria, encomenderos, caciques, abusos, tributos

\section{Les caciques tirés de l'oubli. Ethnies Chachapoya et Chilcho}

\section{Résumé}

Les recherches les plus récentes ont permis de mettre en relief le rôle majeur de certains caciques dans la vie coloniale et ont sorti de l'ombre des ethnies inconnues, ainsi que les sévères abus dont elles furent victimes. Cet article s'efforce de mettre en lumière des faits qui datent du XVlè siècle et se situent dans les départements de Chachapoyas et de Huallaga. Ce travail s'appuie sur des travaux de terrain en archéologie et en anthropologie ainsi que sur des recherches dans les archives péruviennes.

Mots clés : nord-est du Pérou, ethnohistoire, encomenderos, caciques, abus, tribut 


\title{
Rescuing caciques from oblivion: the Chachapoyas and Chilcho ethnic groups
}

\begin{abstract}
Recent investigations permit us to identify some caciques as important actors in the colonial era and to identify some previously unnamed ethnic groups. They also reveal the extent that natives suffered from severe repression. This article highlights specific sixteenth century examples in the Chachapoyas and Huallaga regions, based on anthropological and archaeological fieldwork as well as research in Peruvian historical archives.
\end{abstract}

Key words: northeastern Peru, ethnohistory, encomenderos, caciques, abuses, tribute

\section{LOS INVASORES ESPAÑOLES EN LA ÉPOCA COLONIAL TEMPRANA EN EL PERÚ NORORIENTAL}

El rincón nororiental del Perú en la Ceja de Montaña ha sido dejado fuera de la corriente principal de investigación científica y nunca ha atraído mucha atención. Un estudio desde una perspectiva arqueológica y etnohistórica es de suma importancia para entender las actividades humanas en esta área donde solo en los bosques quedan vestigios arqueológicos. En los archivos emergen algunos nombres de caciques, etnias y españoles en los documentos amarillentos.

Los primeros españoles llegaron a la provincia de Chachapoyas en 1535, tres años después de la primera conquista o invasión europea, penetrando por los pueblos de Cochabamba —un centro administrativo incaico-y después a Longúa, Charrasmal y Gomorá, siguiendo el consabido rumbo al Oriente.

Según los relatos los españoles encontraron a muchas tribus selváticas en esta área en la Ceja de Selva.

El capitán Alonso de Alvarado fue acompañado por el capitán Juan Pérez de Guevara y los caciques Guaman de Cochabamba y Guaquemila, que irrumpieron contra el cacique Igametá, señor de los adversarios.

Los españoles avanzaron hasta el pueblo de Cocax o Coxcón, un lugar desconocido hoy en día (fig. 1) y

«Quedado el camino seguro, los españoles se juntaron los unos y los otros, trayendo los amigos el bastimento que hallaban en la comarca, destruyendo lo que hallaban hasta quemar las casas, que fue tanta la desesperación para los naturales, quellos mismos arruinaron sus campos y pueblos, quejándose a Dios de los cristianos, pues estando en tierras tan lejanas, habían venido a los destruir totalmente» (Jiménez de Espada, 1965, cap. VIII).

Hasta ahora no se han localizado documentos sobre los encuentros entre los incas y las etnias selváticas o entre los incas y los españoles. Garcilaso de la Vega (1967 [1609]: 81) relata la conquista inca hasta Moyobamba y nuestras investigaciones arqueológicas han revelado una notable presencia inca en la provincia de Huallaga (Schjellerup et al., 2003: 2005). Los chachapoya fueron conquistados por los incas alrededor de 1470 y éstos 


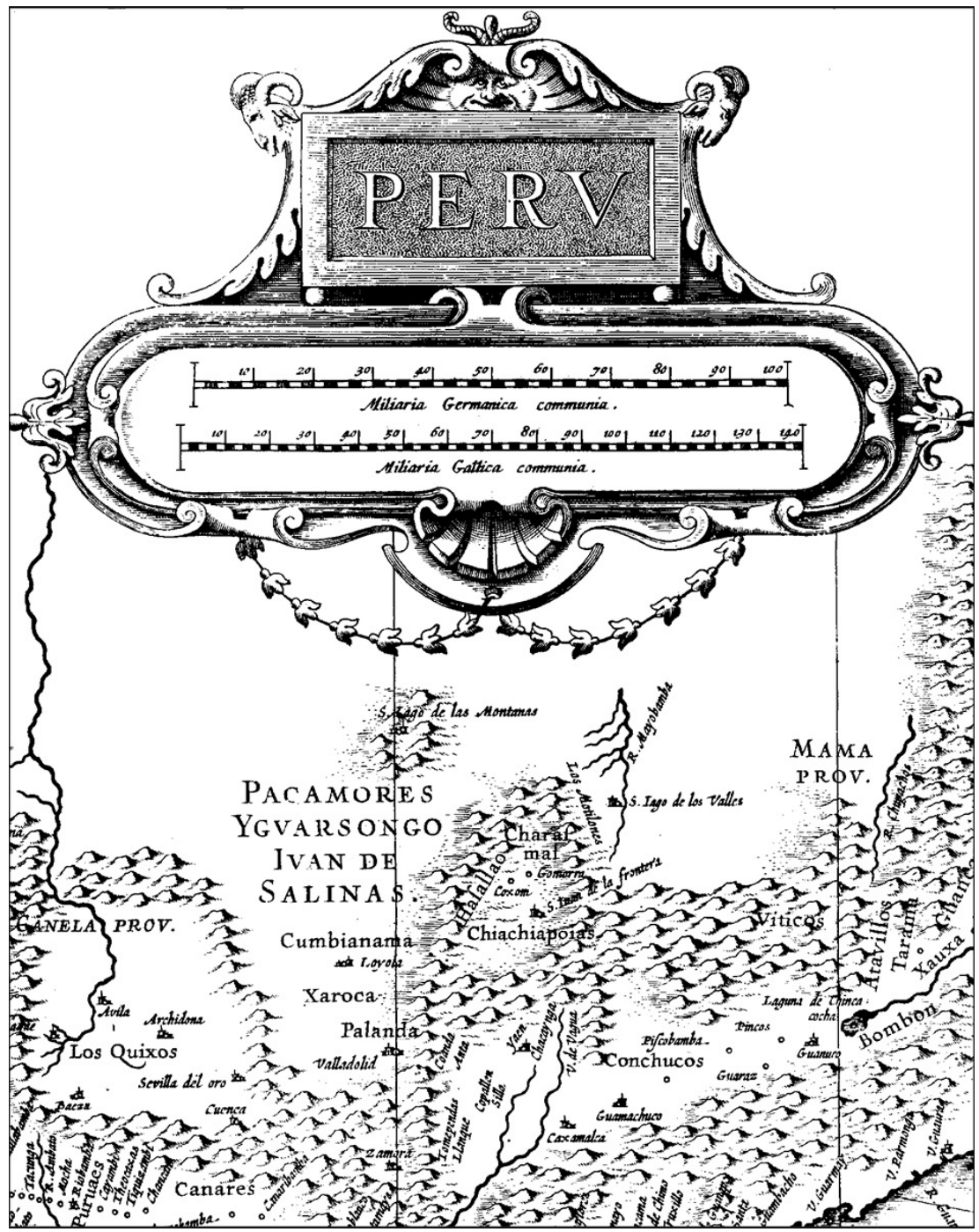

Figura 1 - Parte del mapa del Perú, J. Hondius, c. 1630

(Cortesía de Division of maps, Library of Congress, Washington. D.C.)

introdujeron nuevos estilos arquitectónicos junto con un marcado énfasis en los cultivos para el Estado inca de maíz, algodón y la extracción de oro. Un conjunto de instalaciones tales como centros administrativos (Cascarilla Wasi), tampus (San Juan, Condebamba) fueron construidos al lado de los caminos y otras construcciones menores se alzaron en áreas agrícolas, con la edificación de terrazas (Schjellerup et al., 2003; Schjellerup et al., 2005: 28, 220).

En 1538 Alonso de Alvarado pasó al «descubrimiento» de Moyobamba con Juan Pérez de Guevara: «hallando una tierra áspera y pobre, donde los indios hacían vida selvícola y comían yuca en vez de maíz» (Busto Duthurburo, 1968, Tomo I: 141). 
Por las descripciones tempranas parece que los españoles siempre tomaron una misma ruta desde la ciudad de Chachapoyas hacia la ciudad de Moyobamba para entrar en la selva baja, dejando de lado un área grande del valle de Guayabamba que queda más al sur (fig. 2). Muy poca información ha sido encontrada sobre los paisajes y los indígenas desde el tiempo de la penetración temprana de los españoles, pero varios nombres de etnias están saliendo del olvido como los chilcho, los posic, los laya y los orimono.

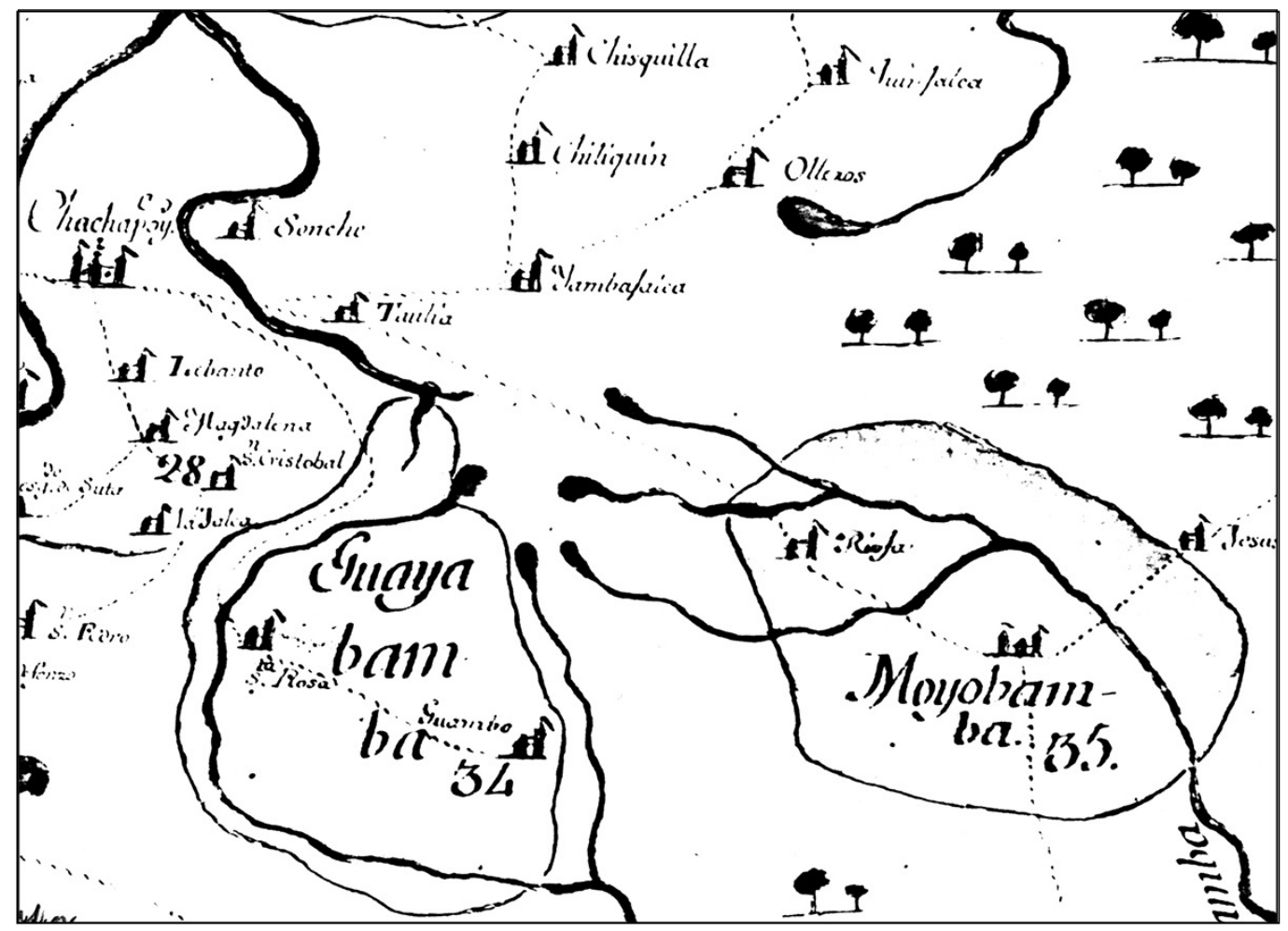

Figura 2 - Parte del mapa de la Intendencia de Trujillo de Guayabamba y Moyobamba

(Martínez Compañón, 1787)

El curacazgo de los chicho y laya parece haber controlado un área que incluía la laguna de los Cóndores al sur, siguiendo la Cordillera Yasgolga, al oeste con una frontera norteña tentativa en ríoTingo/Cerro Tolén y que continuaba hacia el noreste hasta el río Mashuyacu, un tributario del Río Huayabamba, un área mucho más grande que el actual anexo de Los Chilchos. Los chilcho controlaban el acceso a varias entradas naturales que conectaban los Andes con las tierras bajas de la Amazonía, una zonas sumamente importantes para la comunicación y el transporte de los productos de los Andes y de la selva (Schjellerup et al., 2005: 30, 55-56).

Retornando a la provincia de Chachapoyas el capitán Alonso de Alvarado fue nombrado primer encomendero de Leymebamba, Cochabamba y de los indios de Los Chilchos, pero dejó Chachapoyas en 1546. El cacique Guaman ya había muerto y su sucesor el cacique Alonso Quinyop se menciona como cacique de los indios de la sierra con 1000 
tributarios mientras que el cacique Chilcho, también es mencionado como Señor de los Ancingas (Anayungas) naturales y mitimaes y como Señor de los Chontaces que tenía 1500 tributarios (AGl 123: 51v).

Dos años después la encomienda de Alonso de Alvarado fue entregada al capitán Juan Pérez de Guevara el 27 de agosto de 1548 por un decreto de La Gasca.

\section{DISMINUCIÓN DE LA POBLACIÓN}

En aquella época la población ya había sufrido una disminución importante a partir de 1535, donde la parcialidad de los chilcho encabezada por el cacique principal don Hernando Chilcho, se dice había tenido 5 guarangas (5 000 tributarios/35-40 000 personas) y bajó hasta 1500 tributarios durante la encomienda de Alvarado en 1546 y a solamente 1000 tributarios más adelante bajo la encomienda de Juan Pérez Guevara (Espinoza Soriano, 2003: 71). No solo las enfermedades europeas introducidas eran responsables de la gran pérdida de gente sino también los fuertes abusos de los encomenderos.

Las dificultades para estimar el número correcto de los habitantes en los periodos prehispánico y español temprano, han sido abordadas por distintos autores. Han llegado a diferentes conclusiones con relación al número de personas obligadas a tributar, el cual nos permitiría calcular la población total del Perú en diferentes épocas. Rowe ofrece un factor de 5, Smith de 9, Cook propone entre 5 y 9 y Gölte 6 entre número de tributarios y población total (Rowe, 1946: 264; Smith, 1970; Cook, 1981; Gölte, 1973: 265).

De acuerdo con la suposición de que una casa alberga a una familia con 3-4 niños y abuelos sugeriré la presencia de 7 y 8 miembros, lo que significa que el número total de habitantes en el lugar de Los Chilchos (incluyendo a los laya, los chontaces, y los posic) pudo haber alcanzado 7-8 000 personas durante los primeros años de la encomienda de Juan Pérez de Guevara.

\section{EL ENCOMENDERO JUAN PÉREZ DE GUEVARA}

En 1549 Juan de Guevara volvió a Moyobamba y fundó la Ciudad de Santiago de los Valles de Moyobamba en un asiento que en lengua autóctona se llamaba Guaua. Guaua probablemente viene del frutal Guaua (Vicente Villar \& Linci Jara, 1995: 166).

Cinco años después uno de los primeros Agustinos, el Padre fray Juan Ramírez, llegó a la encomienda de Juan Pérez de Guevara de Leymebamba y Cochabamba para fundar el convento de San Augustín de Leymebamba. Como el padre tenía bastante interés en continuar su obra, partió hacia Moyobamba siguiendo los caminos de la ribera de los ríos al este del río del Valle de Los Chilchos.

Gracias a los agustinos tenemos una muy viva y veraz descripción de esa parte al este de la región. Ellos destacan el peligro de viajar a estos lugares debido a la presencia de muchos jaguares. Cuando los misioneros agustinos empezaron su labor de cristianización,

«... avía gran numero de Indios en pocos pueblos, i muchos en diversas i asperas montañas... ay gran abundancia de tigres en aquellas montañas que se entravan en los albergues i chacras de los Indios, i salen a los caminos i pastos de los pueblos despedaçando onbres, mugeres, niños, ganados I animales caseros... estos Indios que abitan en montañas adoran una estrella que llaman Chuquichincay, porque dellas I otras que la acompañan se forma una figura de estrellas que parece tigre a sus ojos, I se piensa que es el que nosotros llamamos signo de Leon, que consta 
de 27 estrellas muy lucientes, dos de primera magnitud, que la una es de major influencia entre todas las del cielo, entra en la imagen a los dos de Agosto, I sale della a los nueve de Setiembre, adoran estas estrellas, que dicen es tigre, porque les defienda destos animales»,

«quando los Indios vieron tan terribles i fieros animales del tamaño de grandes bezerros , i a su miedo mayores de elefantes, o torres, huyendo se bolvian muchos, i ninguno queria passar a ellos, aziendo algunos sumisiones de adorarlos. Alço el buen Padre ojos al Cielo, pidió socorro,.... Y el brioso ministro con valor magestuoso se fue a ellos, que le aguardavan encarniçados, i no era ya poca admiracion de los Indios, viendo que no arremetian adelantandose como solian, mostró una Cruz a las crueles bestias,... se subieron sobre un gran arbol, mostrando solos dientes i miedo. .... Tiró la primera piedra, i otras algunos Indios, sin que los animales mostrasen mas que estar amilanados i rabiosos; animaronse mas Indios, i a pocas pedradas cayeron bramando las terribles bestias, i en el suelo las acabaron de matar, desollaron las pieles manchadas, i trujéjonlas a poner a vista de todos en la plaza publica...» (Los Primeros Agustinos, 1916 [1557]: 383).

Este mismo peligro también es mencionado más adelante por el grupo étnico de los orimona (Espinoza Soriano, 2003: 135), y en la actualidad este problema subsiste para los habitantes de la región (Schjellerup et al., 2003: 132).

\section{EL CASO DE LOS CHILCHO}

Durante el periodo colonial los chilcho sufrieron una carga muy pesada y experiencias traumáticas. Alonso de Alvarado obligó a los chilcho a trabajar en las minas de oro de Santo Thomas de Quillay como mitimaes, probablemente continuando la demanda de trabajo del tributo de los incas.

Sin embargo Juan Pérez de Guevara se dio cuenta del trabajo poco productivo de los chilcho en las minas, donde sufrían las inclemencias del clima frío de la sierra, y para escapar del trabajo duro huyeron montaña adentro, así que él decidió traerlos de vuelta a su lugar de origen (Espinoza Soriano, 2003: 53). Desafortunadamente no hemos podido verificar el texto en el documento original ya que la ubicación del documento es desconocida.

Juan Pérez de Guevara se percató de que indudablemente era mucho más rentable para él obligar a los chilcho a que le pagaran sus tributos en tejidos de algodón y otros productos propios del Valle de Los Chilchos. Y colocó a un Francisco Menacho como mayordomo en 1548 hasta 1550 para supervisar el cultivo y la fabricación de los textiles de algodón y también para controlar el pago del tributo que se transferiría a su casa en Chachapoyas.

Durante una rebelión e invasión de los posic en el Valle de Ipapuy en 1549 el corregidor de Chachapoyas, don Gómez de Alvarado, ordenó a Juan de Guevara a que emprendiera una acción contra las partes implicadas, ya que en aquella época pertenecían todos a su encomienda. Él salió con diez españoles entre los cuales Francisco Menacho y una gran cantidad de gente de Leymebamba y de Los Chilchos (Espinoza Soriano, 2003: 69).

El resultado de la expedición llegó a ser muy violento y varios caciques de los posic fueron matados. Antes de volver al Valle de Los Chilchos, a Francisco Menacho le ordenaron que instalara una estancia de criar chanchos en Posic. Los chanchos debían ser alimentados con maíz, cuyo cultivo se dice que se les enseñaron a los posic. El maíz sirvió no solo para alimentar los chanchos sino también para pagar el tributo (Espinoza Soriano, 2003: 70). 
Los españoles consideraban a los posic como un grupo menos civilizado que los chilcho y para incitar «el proceso de civilización» los posic fueron colocados administrativamente bajo la custodia de don Gómez de Toledo, cacique de los chilcho, pero en tiempos anteriores parece que los chilcho eran aliados con los posic para conseguir acceso a la selva y a sus productos.

Al inicio solamente se usó el maíz para el pago de tributos, pero después se incluyeron los textiles de algodón.

Un tal Francisco Jara fue nombrado por Juan Pérez de Guevara como mayordomo a cargo de educar a los posic en la fabricación de textiles bajo forma de mantas, camisetas y llicllas. Otros cinco españoles se establecieron en Posic y vivieron allí hasta 1556 (Espinoza Soriano, 2003: 70).

\section{EL TRIBUTO}

Excesivas cantidades de 900 piezas de ropa de algodón, 150 panes de cera, 2800 canutos de miel, 5510 ovillos de hilo de algodón, 594 petaquillas de pescado seco, 1054 aves de Castilla, 20 fanegas del maíz, 33 vigas, 46 troncos de la palma de chonta, 50 tablas y 2 camas de madera fueron exigidas de la encomienda de Chilcho y Laya a partir de 1548-1549, y dichas cantidades se incrementaron en los años siguientes (Espinoza Soriano, 2003: 80).

Los mayordomos recibían la parte de su pago en textiles que podían vender. En aquella época, La Gasca todavía no había elaborado ninguna regulación sobre la cantidad de tributos que se podría exigir de la población indígena, así que los encomenderos tenían la libertad de explotar a los indios desvalidos. Incluso cuando las nuevas regulaciones de la tasa se impusieron con fuerza en 1561, Juan Pérez de Guevara se negó a obedecerlas. Esto se convirtió en la razón de un pleito muy notable en la Audiencia de Lima, iniciado por los caciques de Leymebamba y de Los Chilchos en 1564, donde, como se menciona posteriormente, Pérez de Guevara fue finalmente confinado en la cárcel, aunque solo por un periodo muy breve.

En esos años Juan Pérez de Guevara había podido recoger 5077 piezas de algodón, la mayor parte teñido, 394 panes de cera, 7735 canutos de miel, 5610 ovillos de hilo de algodón, 4400 petaquillas de maní, 660 petaquillas de pescado seco, 510 aves de Castilla, 5000 piedras de sal, 90 fanegas de trigo, 200 fanegas de maíz, 60 cargas de chonta y 6 petacas de cobre para clavos (Espinoza Soriano, 2003: 118).

El algodón natural de los chilcho tenía muchos colores que variaban del blanco al marrón (según se pudo identificar en una colección actual (Schjellerup et al., 2003: 122) pero ellos pueden haber tenido otros colores también porque la entrega del tejido de algodón como tributo no se podía dar solamente en un color. Mientras que según parece los españoles en las ciudades más importantes del Perú preferían solamente el blanco, los chilcho tuvieron que teñir su algodón a un color (¿el marrón?) para poder satisfacer al encomendero, porque el algodón teñido se vendía a mejor precio en el mercado. En el pleito en la Audiencia de Lima los chilcho manifestaron estar en contra de teñir su algodón y pedían que el encomendero aceptara los diversos colores del algodón natural (Espinoza Soriano, 2003: 112).

El encomendero con insaciable avidez ordenó a su hermano Francisco de Guevara que viajara con un grupo de los chilcho, de los laya y de los posic para atacar a los orimona, el grupo étnico ubicado lo más lejos al este como he mencionado antes. Los orimona formaban probablemente dos grupos, uno de la sierra y otro del valle (fig. 3). 


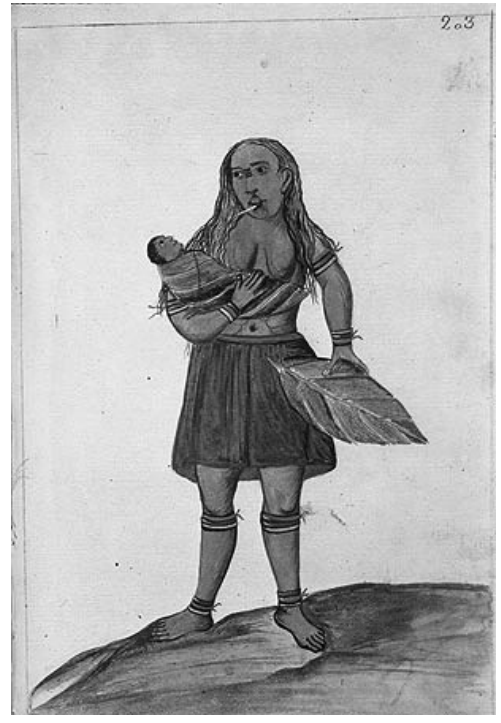

Figura 3 - Yndia de Montaña ynfiel

(Martínez Compañón, 1787)
El asalto fue muy cruel, se desarrolló usando perros de caza y machetes y casi exterminó a toda la población. Sus casas y chacras fueron incendiadas, solamente algunos de los heridos fueron llevados a Posic. Un testigo declaró luego que el ataque había sido realizado solamente a petición del cacique de los chilcho, que argüía que el clima en Los Chilchos era demasiado frío para el cultivo del algodón y no tenían ninguna cera.

La razón expuesta era que los orimona se negaban a cultivar algodón, pese a tener el clima ideal para el desarrollo de esta planta, pero como los chilcho tenían que cumplir con el tributo, se vieron obligados a invadir aquel territorio para sembrar algodón.

Juan Pérez de Guevara enroló probablemente gente de los chilcho, de los laya y de los posic como mercenarios, y con la ayuda de su hermano entró en guerra contra los orimona porque deseaba incluir este área en su encomienda para conseguir más algodón. Uno de los problemas era la administración política de Chachapoyas y de Moyobamba, ya que la encomienda de Pérez de Guevara pertenecía a Chachapoyas mientras que el grupo orimona de la Sierra pertenecía a Moyobamba.

Pero está claro que Juan Pérez de Guevara poseía un poder absoluto y una influencia local abrumadora y podía manipular, amenazar y maltratar a la población indígena causándoles tanto temor que nadie se atrevió a emprender una acción en su contra, hasta el pleito en 1564 y otras quejas (Schjellerup, 1997: 85-91).

La descripción del botín del ataque hace pensar que iba dirigido contra los orimona de la sierra ya que fueron robadas 100 llamas, muchas mantas, ropa, cierta cantidad de ovillos de algodón, muchas cerbatanas, macanas, redes para cazar pájaros y un gran número de cuyes (Espinoza Soriano, 2003: 125).

Otro Jara, Enrique, hermano del mayordomo Francisco Jara, fue encargado por Pérez de Guevara de repartir la tierra de los orimona en nuevas chacras de algodón y también de asegurar la recolección del tributo. Éste cometió una serie de crueldades contra la población de los orimona, ayudado por algunos miembros de los chilcho, de los lajas y de los posic durante los próximos seis años a pesar de las protestas de los encomenderos de los orimona, que vivían en Moyobamba. Los asaltos de los laya y los posic contra los orimona continuaron hasta los años 1570.

Espinoza Soriano enumera las quejas de los caciques. Estos llevaron a la Audiencia de Lima un pleito en contra de su encomendero Juan Pérez de Guevara en 1564. Aquí citamos solamente una selección de las quejas publicadas por dicho historiador (2003: 115-120).

«- Haber permitido que Menacho cortara las narices al indígena Sosia Otano en el pueblo de Ipapuy.

- Haber consentido a Menacho para encerrar en un galpón del pueblo de Pilaya a gran cantidad de indígenas de ambos sexos para que hilaran, tejieran y prepararan ropa, sin proporcionarles alimentos, dando como fruto la huida de ellos a los montes, donde muchos fallecieron de hambre. Mientras que otros fueron capturados a quienes se les amputaron las narices, a otros los descuartizaron —cortándoles las piernas por la parte de musculos a la altura de las corvas- y a los restantes les troncharon las orejas. Entre las víctimas mencionaron a Tipoc Punti y a Quiunti. 
- Que debido a tales abusos, los chilcho escaparon de su pueblo para buscar refugio en los montes de los "indios de guerra" no conquistados todavía, sin poder regresar bajo ningún modo.

- Que utilizaba a una gran cantidad de indígenas en el transporte de los tributos desde sus aldeas a la ciudad de Chachapoyas.

- Que por medio de su criado Diego Pérez logró que los chilcho y laya, aparte de los tributos que le entregaban, le labrasen chacras de algodón, en tanta cantidad que en dos años le cosecharon más de 7000 arrobas (8 $750 \mathrm{~kg}$ ) depositadas en su casona chachapoyana, sin pagarles absolutamente ningún salario».

Mantuvieron a Juan Pérez de Guevara confinado en Chachapoyas en la cárcel solamente durante su declaración donde él negó todas las acusaciones graves. La sentencia del caso es desconocida pero Pérez de Guevara ya estaba libre al poco tiempo. Murió en 1569 y dejó su encomienda a su hijo Francisco de Guevara, quien continuó con los abusos de su padre.

\section{DESPLAZAMIENTO DE LOS CHILCHO}

Alrededor de 1580 el Repartimiento de Chilchos y Laya es un repartimiento separado, atribuido a la Corona española, bajo juridicción del Corregimiento de la Provincia de Caxamarquilla. Contaba con 353 indios tributarios y 1457 personas (ancianos, mujeres y niños) reducidos en las tres pueblos Ilamados Santa Mónica, San Guillermo y El Asiento de Tambo.

En 1583 el Repartimiento de Leymebamba y Cochabamba pertenecía a la encomienda de Juan de Guevara, el segundo hijo de Juan Pérez de Guevara, ya que Francisco había fallecido.

«El Repartimiento de Laymebamba y Cochabamba, bajo don Juan de Guevara, tiene 912 indios pagadores del tributo y 5203 personas, reducidos en las tres aldeas Ilamadas Santo Thomás de Quillay y Elifonso y Cochabamba» (Maurtúa, 1906: 262).

Aparece así que los chilcho fueron reducidos en el pueblo de San Ildefonso de los Chilchos. Sin embargo, la tradición oral en el pueblo actual de Montevideo (anteriormente San Ildelfonso de los Chilchos) cuenta que los habitantes se mudaron de Chilchos (el valle de Los Chilchos) para vivir en otro pueblo a mayor altura, debido a que una enfermedad grave amenazaba con extinguir a la población entera. Puede ser viruela u otra enfermedad (fig. 4).

\section{LA VISITA DE MOGROVEJO}

El obispo de Lima Toribio Mogrovejo visitó Chachapoyas en su segunda visita pastoral en 1593 donde menciona muchos de los topónimos pero con muy pocos habitantes:

«En el pueblo de San Ildefonso de los Chilchos, anexo a esta doctrina (de Sancto Thomas) consta y parece por declaración de don Juan Chilcho y don Pedro Yaxa (Laja) haber cincuenta y seis indios tributarios en los cuales declararon entrar tres cojos y un mudo».

«En la doctrina de Taulia donde es cura el Padre Fray Francisco Cabezón, de la Orden de la Merced, donde dice que el sacerdote tiene que ir con mucho cuidado y recato por causa de los indios Motilones y Jeberos " [i?] que de ordinario salen a Laya y Possi y toda aquella tierra a cortar las cabezas a los cristianos, y todos los caminos son muy malos y peligrosos». 


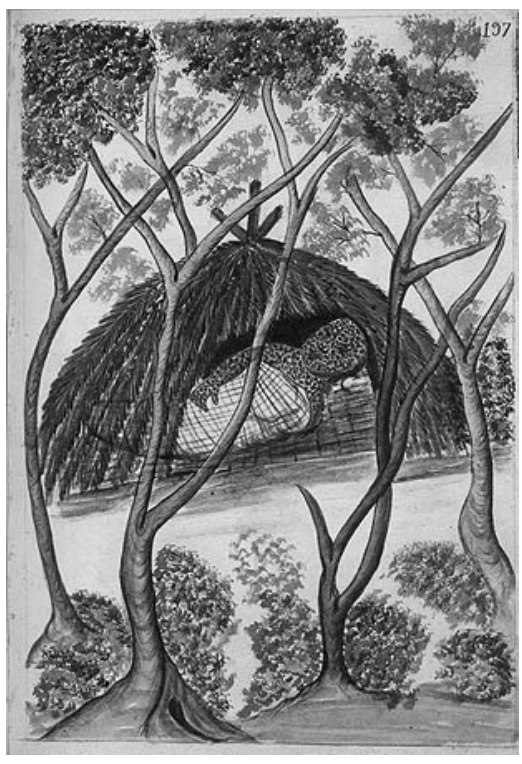

Figura 4 - Yndio con Virüelas

(Martínez Compañón, 1787)
«El pueblo de Laya, el cual por temor de los Ancaes y mal sitio se despobló, y hay tres indios.

El pueblo de Ypapuy, que está siete leguas de muy mal camino con riesgo de los Ancaes y tiene veinte y dos indios tributarios casados, y doce indios viejos reservados, casados y solteros, y doce indias viudas y solteras, y diez y seis mochachos. Confirmó su Señoria en este pueblo once personas.

«El pueblo de Possi, tiene veinte y seis indios tributarios casados y nueve indios más tributarios solteros, y diez indios viejos reservados, casados, y ocho indias, viudas, solteras, y diez y seis mochachos y veinte y dos mochachas, que por todas son ánimas noventa y una. Confirmó su Señoría esta vez en este pueblo veinte y ochos personas. Toda esta población está dentro de la montaña y en tierra peligrosa de enemigos; y la relación de los yanaconas ovejeros de las estancias está en la información que hizo su Señoría, que está en este libro, y todas son anexos a esta doctrina; y más, tiene acá afuera en la sierra fuera de la montaña los pueblos y gente e indios...» (Mogrovejo, 1921: 51, 65).

La mayoría de los asentamientos en la montaña parecen haber desaparecido en el siglo XVII como es el caso de los pueblos reducidos de Santa Mónica, San Guillermo y El Asiento de Tambo en el repartimiento de Chilchos y Laya ya que estaban mencionados diez años antes. Es posible que hayan sido poblados solamente por un tiempo muy corto o tal vez que no llegaran a existir siquiera. Encontramos un decrecimiento muy dramático de la población en los primeros 50 años después de la Conquista con marcados abusos de los invasores españoles.

En 2004 hicimos investigaciones interdisciplinarias de arqueología, etnohistoria, antropología y geografía en el valle de Los Chilchos que pertenece geográficamente a la provincia de Huallaga pero está adscrito administrativamente a Leymebamba en la provincia de Chachapoyas.

No tenemos ninguna referencia de dónde estaban situados estos tres pueblos. Los topónimos de Laja, Posic y de los pueblos de Ipapuy, Ipoala y de Jibil no constan en ningún mapa contemporáneo pero la tradición oral entre algunos habitantes ubica el pueblo original de Posic al suroeste de Soritor. Sería distinto del lugar cerca de Rioja que lleva hoy día este mismo nombre de Posic.

Otros grupos de la Ceja de Montaña vivían a lo largo del río Huambo, un tributario del río Huayabamba durante el mismo periodo pero en este caso también solo aparecen los topónimos en los documentos sin que haya supervivientes. 
Sacando a los caciques de la oscuridad del olvido. Etnias chachapoya y chilcho

\section{Referencias citadas}

\section{Fuente primaria}

Archivo General de Indias (AGI)

AGI Patronato Real, Legajo 123 Ramo 4. Año 1578. «Información de los meritos y servicios del Capitan Juan Perez de Guevara, uno de los conquistadores y pacificadores del Peru y particularmente de la provincia de los Chachapoyas».

\section{Fuentes segundarias}

AGUSTINOS, LOS PRIMEROS, 1916 [1557] - Relación de la religión y ritos del Perú hecha por los primeros religiosos Agustinos que alli pasaron para la conversion de los naturales. In: Colección de Libros y Documentos referentes a la Historia del Perú, Tomo XI: 3-56; Madrid.

BUSTO DUTHURBURU, J. del, 1968 -Diccionario Histórico Biográfico de los Conquistadores del Perú. Tomo I, Letra A; Lima: Editorial Arica S.A.

COOK, N. D., 1981 - Demographic Collapse; Indian Peru 1520-1620, 310 p.; Cambridge.

ESPINOZA SORIANO, W., 2003 - Juan Pérez de Guevara y la historia de Moyobamba, siglo XVI, 274 p.; Lima: Derrama Magisterial.

GARCILASO DE LA VEGA, Inca 1966 [1609] - Royal Commentaries of the Incas, 264 p.; Austin: University of Texas Press. Translation by Harold Livermore.

GARCILASO DE LA VEGA, Inca 1967 [1609] - Commentarios Reales de los Incas, Tomo I-IV, 212 p. + 215 p. + 195 p. + 189 p.; Lima: Reproducción de 1. Edición por la Universidad Nacional Mayor de San Marcos.

GÖLTE, J., 1973 - Bauern in Peru, 396 p.; Berlin.

MAÚRTUA, V. M. (ed.), 1906 - Juicio de Límites entre el Perú y Bolivia. Virreinato peruano. Tomo I, 387 p.; Barcelona: Heinrich.

MOGROVEJO, T. A. de, 1921 [1593] - Diario de la segunda visita pastoral, que hizo de su arquediocesis el Ilustrisimo Señor Don Toribio Alfonso de Mogrovejo, arzobispo de los Reyes. Revista del Archivo Nacional del Perú, Tomo II, Entrega I: 37-78; Lima.

JIMÉNEZ DE LA ESPADA, M. (ed.), 1965 [1557-1586] - Relaciones Geográficas de Indias, Ixvi $+415+343+318$ p.; Madrid: ediciones Atlas. Biblioteca de Autores Españoles, Vols. 183-185.

ROWE, J. H., 1946 - Inca culture at the time of the Spanish conques. In: Handbook of South American Indians, Bulletin 143, vol. 2: 183-330; Washington: Bureau of American Ethnology.

SCHJELLERUP, I., 1997 - Incas and Spaniards in the Conquest of the Chachapoyas. Archaelogical, Ethnohistorical and Anthropological Research in the North-eastern Peru, 343 p.; Göteborg: Göteborg University. GOTARC Series B. Gothenburg Archaeological Theses, $\mathrm{n}^{\circ}$ 7. Publicado en español en 2005: Incas y Españoles en la Conquista de los Chachapoya, 641 p.; Lima: PUCP, IFEA.

SCHJELLERUP, I., KAMP SØRENSEN, M., ESPINOZA, C., QUIPUSCOA, V. \& PEÑA, V., 2003 - Los Valles Olvidados, Pasado y Presente en la Utilización de recursos en la Ceja de Selva, Peru/ The Forgotten Valleys, Past and Present in the Utilization of 
Resources in the Ceja de Selva, Peru, 444 p.; Copenhagen: The National Museum of Denmark. Ethnographic Monographs, $\mathrm{n}^{\circ} 1$.

SCHJELLERUP, I., QUIPUSCOA, V., ESPINOZA, C., PEÑA, V. \& KAMP SØRENSEN, M. 2005 - Redescrubriendo el Valle de los Chilchos, Condiciones de Vida en la Ceja de Selva, Perú/ The Chilchos Valley Revisited, Life Conditions in the Ceja de Selva, Peru, 424 p.; Copenhagen: The National Museum of Denmark. Ethnographic Monographs, $\mathrm{n}^{\circ} 2$.

SMITH, C.T., 1970 - Depopulation of the Central Andes in the 16th Century. Current Anthropology, Vol. 11, no 4-5: 453-464.

VICENTE VILLAR, C. G. \& LINCI JARA, J., 1995 - Historia de Moyobamba 1590. Revista del Archivo General de la Nación, Vol. 12: 161-168; Lima. 